\title{
We don't know what we need to know about atrial fibrillation
}

\author{
Patrick M. McCarthy, MD
}

From the Bluhm Cardiovascular Institute, Division of Cardiac Surgery, Northwestern University, Chicago, Ill. Disclosures: P.M.M.: Edwards Lifesciences: consultant, royalties, intellectual property; Abbott Vascular: consultant; Medtronic: educator.

Received for publication Dec 19, 2017; accepted for publication Dec 20, 2017; available ahead of print Feb 2, 2018.

Address for reprints: Patrick M. McCarthy, MD, Bluhm Cardiovascular Institute, Division of Cardiac Surgery, Northwestern University, 201 East Huron St, Suite 11-140, Chicago, IL 60611-2908 (E-mail: pmccart@ nmh.org).

J Thorac Cardiovasc Surg 2018;155:1522-3

$0022-5223 / \$ 36.00$

Copyright $\subset 2018$ by The American Association for Thoracic Surgery

https://doi.org/10.1016/j.jtcvs.2017.12.100

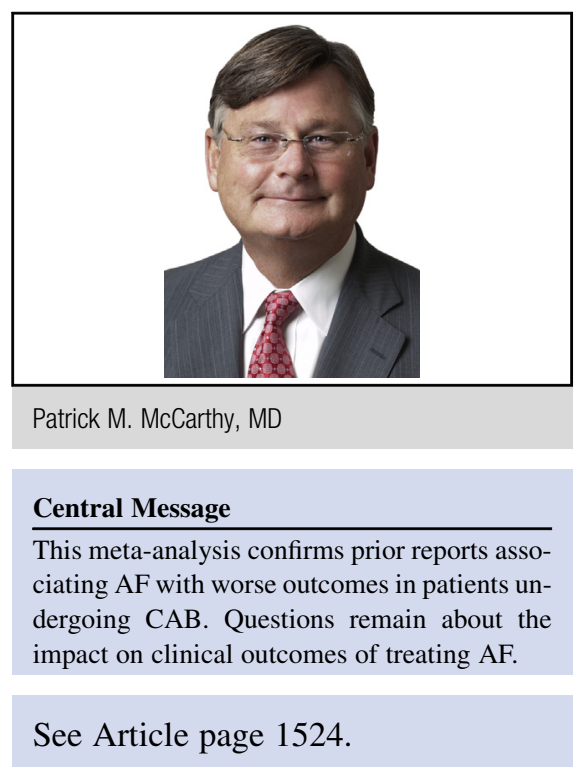

Atrial fibrillation (AF) is encountered in older patients and sometimes preoperatively in patients undergoing coronary artery bypass $(\mathrm{CAB})$. Prior single-center studies, Society of Thoracic Surgeons database studies, and a Cochrane review indicate that $\mathrm{AF}$ is associated with increased risk for these patients. ${ }^{1-3}$ The meta-analysis from Saxena and colleagues ${ }^{4}$ confirms these prior reports and notes an association of preoperative $\mathrm{AF}$ with higher stroke, renal failure, reoperation for bleeding, prolonged ventilation, and higher early and late mortality. Unique to this analysis was an attempt to determine whether off-pump CAB mitigates those risks, and with the limited data available, it appears not. They conclude that there is "a need to evaluate the role of adjunctive ablative strategies." 4

We know from randomized trials that surgical concomitant $\mathrm{AF}$ ablation (SAF) reduces late $\mathrm{AF}$ when compared with control patients (untreated AF), although the majority of these studies are in patients undergoing mitral surgery, not $\mathrm{CAB} .^{2}$ The frequency of $\mathrm{AF}$ is higher in patients undergoing mitral surgery; therefore, trial enrollment is more practical than a CAB trial. Single-center and Society of Thoracic Surgeons database studies indicate that SAF can be performed safely and may even reduce perioperative risks compared with patients with untreated $\mathrm{AF}^{5,6}$ On the basis of available data, the Society of Thoracic Surgeons and Heart Rhythm Society in 2017 made it a Class 1 recommendation to ablate preoperative $\mathrm{AF}$ at the time of $\mathrm{CAB}$ (and mitral and aortic valve surgery), ${ }^{7}$ but in general the surgical community has not. ${ }^{7,8}$ Data indicate that SAF is performed in only $33 \%$ of patients undergoing $\mathrm{CAB} .^{5}$

What we don't know is critical. If we extend SAF to the $67 \%$ of patients currently untreated, will we increase their risk? Good surgeons may have used good judgment not to treat all patients. We can't easily dissect that decision out using registries, propensity-matched studies, and metaanalyses. Surgical randomized trials generally exclude a large percentage of potential candidates from enrollment. What is the right treatment to add? Because stroke is the most dreaded and lethal AF complication, should the treatment be focused on the left atrial appendage, and if so, excise, clip, oversew, or other? ${ }^{9}$ If SAF, which lesion set? Is the best approach pulmonary vein isolation with clamps, open the left atrium for a box pulmonary vein lesion with ablation to the mitral isthmus, or open both atria for a more complete ablation? ${ }^{10}$ Which technology: cryoablation alone or with bipolar radiofrequency clamps? Patients treated with SAF will have less AF, so their electrocardiogram will look better, but will that translate into longer lives, less strokes, a better quality of life, reduced rehospitalizations, and less cost of care over time? Are there subgroups in whom the risk/benefit calculation varies? Perhaps young patients with symptomatic AF derive benefit at low risk, but elderly patients with comorbidities do not? No surprise in the meta-analysis that patients with AF don't do as well as those without preoperative AF, but there are no answers to the questions that count. The field of SAF ablation has to focus on those questions now, but the answers will be hard to find.

\section{References}

1. Quader MA, McCarthy PM, Gillinov AM, Alster JM, Cosgrove DM III, Lytle BW, et al. Does preoperative atrial fibrillation reduce survival after coronary artery bypass grafting? Ann Thorac Surg. 2004;77:1514-24.

2. Huffman MD, Karmali KN, Berendsen MA, Andrei AC, Kruse J, McCarthy PM, et al. Concomitant atrial fibrillation surgery for people undergoing cardiac surgery. Cochrane Database Syst Rev 2016;8:CD011814.

3. Shahian DM, O'Brien SM, Filardo G, Ferraris VA, Haan CK, Rich JB, et al. The Society of Thoracic Surgeons 2008 cardiac surgery risk models: Part 1 - coronary artery bypass grafting surgery. Ann Thorac Surg. 2009;88(1 Suppl):S2-22. 
4. Saxena A, Virk SA, Bowman S, Chan L, Jeremy R, Bannon PG. Preoperative atrial fibrillation portends poor outcomes after coronary bypass graft surgery: A systematic review and meta-analysis. J Thorac Cardiovasc Surg. 2018;155: 1524-33.e2.

5. Badhwar V, Rankin JS, Ad N, Grau-Sepulveda M, Damiano RJ, Gillinov AM, et al. Surgical ablation of atrial fibrillation in the United States: trends and propensity matched outcomes. Ann Thorac Surg. 2017;104:493-500.

6. Rankin JS, Lerner DJ, Braid-Forbes MJ, Ferguson MA, Badhwar V. One-year mortality and costs associated with surgical ablation for atrial fibrillation concomitant to coronary artery bypass grafting. Eur J Cardiothorac Surg. 2017;52:471-7.

7. Calkins H, Hindricks G, Cappato R, Kim YH, Saad EB, Aguinaga L, et al. 2017 HRS/EHRA/ECAS/APHRS/SOLAECE expert consensus statement on catheter and surgical ablation of atrial fibrillation. Heart Rhythm. 2017;14: e275-444.

8. Badhwar V, Rankin JS, Damiano RJ Jr, Gillinov AM, Bakaeen FG, Edgerton JR, et al. The Society of Thoracic Surgeons 2017 clinical practice guidelines for the surgical treatment of atrial fibrillation. Ann Thorac Surg. 2017; 103:329-41.

9. Elbadawi A, Ogunbayo GO, Elgendy IY, Olorunfemi O, Saad M, Ha LD, et al. Impact of left atrial appendage exclusion on cardiovascular outcomes in patients with atrial fibrillation undergoing coronary artery bypass grafting (from the $\mathrm{Na}$ tional Inpatient Sample Database). Am J Cardiol. 2017;120:953-8.

10. Churyla A, Iddriss A, Andrei AC, Kruse J, Malaisrie SC, Passman R, et al. Biatrial or left atrial lesion set for ablation during mitral surgery: risks and benefits. Ann Thorac Surg. 2017;103:1858-65. 